\title{
Telangana Social Welfare Residential Educational Institutions Society: Programs and Facilities available for Teachers Empowerment
}

\author{
Bollam Karunakar
}

Research Scholar, DR. B.R. Ambedkar Open University, Hyderabad, Telangana, India

Corresponding author: karnab123@gmail.com

Received: $22-02-2020$

Revised: 24-06-2020

Accepted: $29-07-2020$

\begin{abstract}
This article explores the programs and facilities available for teacher empowerment in Telangana Social Welfare Residential Educational Institutions (TSWREIS) and quality based education to the marginalized children. This paper analyses the professional development of teachers against the background of acquisition of skills for the 21st century. Teachers and students of TSWREIS are working day and night with the dedication to propel the Society to the global map within six years. The TSWREIS carved a niche for itself by its seamless experimentation and syncing with the emerging trends in the education space. Residential schools achieved $96.63 \%$ in SSC, $84.31 \%$ in Intermediate and about $85 \%$ in Degree results in the academic year 2018-19. In 2019, 53 students got admission into MBBS, 20 in IIT's, 48 in NIT besides getting admissions in professional institutions like Delhi University, Ajim Premji University, and TATA Institute of Social Sciences. The National Curricular Framework of India (NCF) states clear expectations for teachers to move away from teacher-centred instructional approaches to student-centred teaching that involves children in active engagement through inquiry, questioning, debates, exploration, application and reflection, leading to theory building and the creation of new ideas. Teachers are the most significant influence on student learning. To produce good students, an institute needs to have good teachers, those who are continuously learning and enhancing their skills. Society is investing time and money in the development of their teachers. As teachers learn and augment their skills, they are more likely to be engaged in their jobs, engage better in the classroom.
\end{abstract}

Keywords: Residential school, Scheduled Castes, Teachers empowerment, Marginalized children, Quality Education

Telangana Social Welfare Residential Educational Institutions Society (TSWREIS) under the aegis of the Ministry of Scheduled Caste Development, Government of Telangana, has been passionately working to place the poorest among the Scheduled Castes in the prosperous orbit through quality education for the last 35 years. This Society, with 268 institutions with about 1,50,000 students, has been providing quality education in English medium upto graduation, and students cover roughly $10 \%$ of cohorts among all SCs in Telangana. TSWREIS runs high schools, junior colleges, and degree colleges covering both arts and sciences.
Teachers are the architect of the student's life. Teachers make their students learn that they are lifefriendly and good for them, and instills confidence in them. They help them to be the best version of themselves throughout life. Teachers update their students from time to time. They let their students know the importance and meaning of their life. They strengthen them perform better in life, make the best choices for their life survival.

\footnotetext{
How to cite this article: Karunakar, B. (2020). Telangana Social Welfare Residential Educational Institutions Society: Programs and Facilities available for Teachers Empowerment. Educational Quest: An Int. J. Edu. Appl. Soc. Sci., 11(2): 133-139.
}

Source of Support: None; Conflict of Interest: None 
Education is the key to all-round human development. The education development of a nation measured with its economic, social, and cultural progress of citizens. India is a pluralist country with rich diversity reflected in the multitude of cultures, religions, and languages of various groups. There is a however significant disparity in the socio-economic parameters of multiple groups/communities residing in the country. Some groups, notably the Scheduled Castes, have been traditionally marginalized and economically backward with the total population of the country. Educational development is the most effective instrument for their empowerment, and it has the potential to help the marginalized and the poor to come out of the poverty trap, and facilitate them to be on par with the rest of the citizens.

The residential schools' Society is empowering schools is about the following:

1. Valuing the work by the teacher

2. Enabling the teacher to be confident

3. Providing teachers with genuine job enrichment

4. The actual influence of what is going on in the school

The Society is recognized as the significant need for teacher empowerment stems from the following:

1. Empowered teachers are actively involved in the reform of their schools, curriculum, pedagogy and classrooms.

2. Through teachers flow the ideology, values, and culture of a nation, state, and its people.

3. To increase student access, learning and retention in education relevant and empowering teacher education is crucial.

4. Increases teachers' job satisfaction commitment and sense of collegiality for school improvement.

Being under the blessing of good teacher bring ultimate satisfaction and peace in the way of thinking, a student can live a happy and successful life, and teachers make their students mind innovative by the way they are. They do not mind telling the importance of student's life whether they lose or they win. They are the giver of fragrance to the student's soul, mind, and heart. Not the kind that makes them emotionally weak, not the kind that compromises on their intellect, not the kind that breaks them. Teachers should be role models and give the right direction to the lives of their students. Life of students by imparting the knowledge that made them learns and accepts with respect. Residential schools provide valuebased education in a stress-free environment, which enables the students to determine their inner talents and flourish them to the fullest potential. Residential schools broaden the vision and enlighten the way to the future of a child by the totality of discipline, which called education. The mission of the Telangana Social Welfare Residential Educational Institutions is to promote a wide range of curricular and extracurricular activities. Beyond the cones of classrooms to create a vibrant teaching and learning environment and help marginalized students realize their full potential in every sphere of life in the $21^{\text {st }}$ century.

\section{Literature Review}

The review of the literature also indicates that only a few studies conducted in the field of residential education and no research designed on the Telangana Social Welfare Residential Educational Institutions Society (TSWREIS). The profession of a teacher in ancient India had a very high code of honour. The duty of the teacher to transmit knowledge or cultural heritage to the future generation was imperative. It was a sort of social obligation. Education was imparted free of charge. The residential school is an old pattern in Indian Education since the Vedic Age, which we called Gurukul. The system of Gurukul was very different from other methods of teaching or learning of any education or technique. Now a day, its value or scope rises more discipline among the management and teaching staff and the methodology of schooling that varies from other education patterns. Residential care programs had been widely recognized as an integral part of child welfare programs to help marginalized children. Teacher empowerment is to improve student learning by fostering teaching quality. Teacher empowerment is affected by factors like the nature of teaching, the features of teaching as a profession, teacher background knowledge, school organizational features, and its environmental context. 
According to (Bolin, 1989) teacher empowerment requires investing in teachers the right to participate in the determination of school goals and policies and the right to exercise professional judgment about the content of the curriculum and means of instruction. The study of (Etzioni, 1968) led to the conclusion that "Empowered teachers with increased task motivation, enhanced feelings of meaning, and strong organizational commitment are the foundation of dynamic school technology. Schools can create the conditions in which teachers, as empowered actors, can freely exercise their expert judgment, deal effectively with non-routine challenges, change social structures and, in turn, depend on changed structures for self-advancement. Collaborative social structures, including selfmanaged teams, can serve as vehicles through which the goals of education professionals and schools achieved."

An empirical study by (Dee et al. 2003) based on Spreitzer's definition of empowerment demonstrated that empowered teachers showed higher levels of organizational commitment. (McKenna, 1990) study indicates that empowerment is a building of personal self-esteem and possibly the motivation for the worker to further their training and education. (Marks \& Louis, 1997) reported that teacher empowerment is an essential condition for enhancing students' academic performance. The effects of teacher empowerment on their job satisfaction, self-efficacy, and morale have examined. However, little research carried out to display its results as an expanded commitment to teaching and students. The relationship between empowered and committed teachers instead of those who are less empowered has not well examined. Edmonds (1979) stated that a large body of research had performed on potential environmental characteristics that may enhance teacher empowerment. Research has indicated high expectations for student learning, and necessary skills as the critical environmental characteristics of effective schools. (Elmore \& And Others, 1990) suggested transforming school structure, work conditions, and decision-making processes in school organizations as strategies to improve teaching. (Firestone \& Pennell, 1993) pointed out that teacher commitment needs to be examined precisely by placing it within student dimensions. This study focused on teacher commitment within the instructional activities of teachers. Teacher commitment to teaching studied with the expectation that it can contribute to our understanding of student learning. The results showed that this did not make any contribution to student achievement. (Maeroff, 1988) concluded that teacher empowerment consists of improved status, increased knowledge to access to decision-making.

\section{Research Questions}

The main aim of this study is to explore the Telangana Social Welfare Residential Schools in respect of programs and facilities available for teacher's empowerment. The present study addressing the following research questions:

1. What are the programs and facilities available for teacher empowerment?

2. What are the results and achievements of TSWREIS?

3. What is the feedback on teacher empowerment programs?

\section{Objectives of the study}

The present study addressed the following objectives:

1. To explore the programs and facilities available for teacher empowerment.

2. To find out the results and achievements of teacher empowerment programs.

3. To highlight the feedback of students and teachers.

\section{Methodology}

This study adopted the Qualitative research approach, Survey design approach and collected data from primary and secondary sources. Students, teachers, and principals are the participants of the study. The research sample selected randomly from the population. Data for the study collected from three sources, they are:

1. Documents available in the institutions

2. Responses of 120 teachers and principals with the help of a questionnaire and interview schedule

3. Feedback and answers from the 300 students with the help of an interview schedule. 


\section{RESULTS AND DISCUSSION}

This paper analyzes the programs and facilities available for teacher empowerment in the Telangana Social Welfare Residential Educational Institutions Society. The Society has been working with the noble aim of providing quality education to the needy and deprived children on par with the other advantaged children. The Society has been striving to provide the highest standards of education and to achieve this mission; several innovative practices were introduced as part of the Five-Point Plan (P5) to promote distinctive teaching and learning environment that empowers both students and teachers:

1. Continuous empowerment of students, teachers, and principals.

2. Improving the environment to promote quality in both teachings and learning in the school.

3. Promoting a healthy and competitive spirit among students, teachers, schools, and zones.

4. Intensifying the use of technology in both academic and administrative activities.

5. Enlisting community participation by tapping the potential of parents, alumni, mentors, and volunteer.

Empowerment is a process wherein school participants develop and display the competence to take charge of their growth and resolve their problems. Empowered teachers believe they have the skills and knowledge to act in a situation and improve it.

\section{Teacher Empowerment Programs}

Teacher empowerment program plays a significant role in every educational institution, and it enables the teachers to improve their pedagogical practices, classroom management techniques, and leadership skills. Teacher empowerment is a process of professional growth and development that allows teachers to exercise their professional judgment about the methods to be followed to transform the teaching and learning environment in an endeavour to build institutions of academic excellence. Teacher empowerment programs are planned and executed based on the needs and following three significant steps:
1. Need-based at the school level,

2. Individualized and Mentoring, and

3. Supervising the progress of the training.

\section{Subject Enrichment Programs}

The SCERT Resource Team and subject experts are conducting regular training on classroom management techniques and innovative teaching methods to augment the teaching and classroom management skills of teachers and principals.

\section{Career Counseling}

Selected groups of teachers are trained by in Career Counseling, and these trained teachers assist the students of classes IX to Inter in choosing career opportunities and universities of higher education. Junior lecturers from all the institutions were imparted training in career counselling to guide the students through the career path. The participants will, in turn, guide the students on various career opportunities.

\section{IMMERSION - Training in Communication Skills}

Training in communication skills named 'Immersion' is imparted to all the teachers who require it with the experts in the field. The teachers identified through classroom observations, external panel inspection reports, NQP seminars. Homework and assignments are given to the teachers. They practice those assignments at their respective schools. The concerned principal monitors the progress of the teachers and provides a feedback report to the academic wing for initiating further necessary bridging programs. The participants selected through a baseline test are required to attend the training a minimum of 50 hours.

\section{Teacher Exchange Program}

This program facilitates to trade places with another teacher in another institution for a week. The selected teachers get to learn how teachers teach, and students learn and observe good practices in other schools. This program gives excellent relief for teachers tired of the routine at their home institutions and helps them to get motivated and be back on track. At the end of the program, teachers return to their schools and share what they have learned with their colleagues and classrooms 
and start implementing the best practices at self institution. This program also helps the teachers to correct their own mistakes in the teaching-learning process.

\section{Mentor-Mentee Program}

New quality Policy 2016 introduced to empower the teachers and strengthen the academics in TSWRE Institutions. As a part of its, Mentor-Mentee Program started in the year 2016 in all the regions of Telangana State. This academic year witnessed much shuffling of the principals and staff in all the TSWRE institutions: many new educational programs, both curricular and co-curricular activities incorporated into the academic calendar.

\section{NQP Seminars}

The TSWREIS introduced a unique New Quality Policy (2016) under the P- 5 Model (2012) to empower teachers to meet the challenges of the 21st century and to uplift the academic standards of the students. The NQP offers an opportunity for all the teachers to look into themselves and also provides an idea to assess themselves concerning the latest developments in teaching and learning practices. The teachers are working beyond the call of their duty and trying to provide quality education to the children on par with the other advantaged children. NQP focuses on encouraging teachers to employ the latest technologies and innovative teaching methods. The NQP primarily designed to help teachers and the staff members realize their full potential. The components of the NQP are seminars, mentoring, internship, inter society teacher conclaves, T-Plus clubs, peer evaluation, institutional accreditation, life skills studios, listening skill enhancement, and internal standards board.

\section{Strategy Meetings}

Strategy meetings conducted every week at the school level to monitor the weekly academic progress of the students, coverage of syllabus, implementation of policies and programs to promote academic excellence.

\section{School Leadership Excellence}

The School Leaders training programs include participation in workshops, seminars, conferences conducted by NCERT, EGMM, CFBT, and CII. The
Society is organizing field visits to other reputed public schools in and outside the state to learn the best practices, development of various skills such as life skills, administrative and financial management skills, and CCE.

\section{Training in Counseling}

Mano Jagruti, Challa's Counseling Centre Hyderabad, is training teachers in counselling to address student's emotional, psychological, and growing up problems.

\section{Librarian's Training}

Hippo Campus, Bangalore is conducting training programs on 'Grow by Reading' methodology, a method in which the books in the library are categorized and arranged according to various colours (Green, Red, Orange, White, Blue, Yellow) indicating different levels

\section{Reading Wise Training}

The Society is providing training on innovative teaching techniques to develop teaching skills and multiple intelligences for the teachers of English, Mathematics, Science and Social Sciences from $5^{\text {th }}$ to $10^{\text {th }}$ classes.

\section{ELT Workshops}

RIE, Mysore is providing training to TOTs, and they are conducting the seminars and training to TGTs and CRTs in English. The Society is imparting Language Training (ELT) workshops for all the TGTs and CRTs.

\section{Flipped Classroom Practices}

The principal objective of the flipped classroom is to engage students in the active learning process than passive recipients. It is a pedagogical model in which the typical traditional lecture methods reversed. The students read a particular topic at home before the actual class session, unlike in a conventional classroom.

\section{Teacher Plus Club (T-Plus Clubs)}

It is a club activity wherein the teachers discussed a given topic in English and aimed at improving English communication and discussion skills among the teachers. It conducted every Monday and Tuesday of the week. 


\section{Test and Teach}

In Test and Teach program, the teachers assign a topic to be taught to the students the previous day and conducts an evaluation test on the comprehension of the student on the topic the next day. This method enables the teacher to understand the student's knowledge of the issue and evolve various techniques and strategies to teach the subject.

\section{Panel Academic Inspections}

The TSWREIS conducts regular panel academic inspections in all TSWR Institutions with the help of retired academicians from Kendriya Vidyalas, JNVs, and other reputed public schools. The academic panel inspections conducted to assess the quality and performance of schools, teachers, and students. It also aims to identify the weak and active areas of the schools to plan programs to improve academic standards.

\section{Quality Assessment Program}

An agency empanelled by CBSE is conducting quality assessment programs to assess the quality of teaching and learning in TSWRE Institutions

\section{Subscription of Newspapers and Magazines}

School libraries subscribed Teacher Plus and Civil Society Magazines and The Hindu, The Hans India and a vernacular

\section{Drop Everything and Read (DEAR)}

DEAR is the TSWREIS's new mantra to inculcate reading culture among teachers, students, and staff, during this time they have to stop whatever they are doing and read for 20 minutes on hearing a long bell during school hours. The time utilized for reading something other than textbooks, like newspapers, novels, or magazines.

\section{Drop Everything and play (DEAP)}

DEAP is a new and unique initiative by the TSWREIS, which allows teachers, students, and staff to play all-day leaving their classwork, and aimed at distressing from the academic load and reduce cognitive burden among teachers. Not just students, teaching and non-teaching staff have to take up a sport or game of their choice as part of the initiative and play for an entire day.

\section{Academic Achievements}

Teacher training is continuous and intended to provide the teachers with the skills and knowledge necessary for the provision of education to students. Teacher empowerment programs and students' academic performance are interrelated and developing social skills, personality progress, intellectual skills, moral values, and character appeal in students. SSC, Intermediate, and Under Graduate examinations results proved the efforts and handwork of teachers. Residential schools achieved $96.63 \%$ in SSC, $84.31 \%$ in Intermediate and about $85 \%$ in Degree results in the academic year 2018-19. TSWREIS students have been making the Society proud with the active support of the Telangana Government getting admission into IITs, NITs, Medical Courses, CCIP(USA), TISS. In 2019, 53 students got admission into MBBS, 20 in IIT's, 48 in NIT besides got admissions in professional institutions like Delhi University, Ajim Premji University, and TATA Institute of Social Sciences. Mr Akunuri Naresh, an alumnus of Social Welfare Residential School, Narsampet, Warangal and Social Welfare Residential Junior college, IIT Nagole chased his most cherished dream of becoming an Indian civil servant and secured 782 rank in the highly prestigious and competitive UPS Exam 2019 on his third attempt.

\section{CONCLUSION}

With the spirit of the Constitution of India, the Society is passionately working to place the poorest among the Scheduled Castes in the prosperous orbit through quality and equitable education for the last 35 years with 268 institutions and about 1,50,000 students in English medium up to graduation. Teachers have a positive attitude towards the training programs offered by the Society. They used training sessions for professional development, and students are delighted with the professionalism of teachers. The Society offered training programs are using for the development of professional skills in teachers as well as for personal growth. These teacher empowerment programs are helping students to achieve amazing results with classroom learning programs. Gurukul teachers are introducing students like Malavath Poorna to the community to inspire students to climb life higher peaks in the future. 


\section{REFERENCES}

Bolin, F.S. 1989. Empowering Leadership. Teachers College Record, 91(1): 81-96.

Dee, J.R., Henkin, A.B. \& Duemer, L. 2003. Structural antecedents and psychological correlates of teacher empowerment. Journal of Educational Administration, 41(3): 257-277.

Elmore, R.F. \& And Others. 1990. Restructuring Schools: The Next Generation of Educational Reform. The JosseyBass Education Series. Jossey-Bass Inc. https://eric. ed.gov/?q=Elmore+(1990)+\&id=ED356519
Firestone, W.A. \& Pennell, J.R. 1993. Teacher Commitment, Working Conditions, and Differential Incentive Policies. Review of Educational Research, 63(4): 489-525.

Maeroff, G.I. 1988. The Empowerment of Teachers: Overcoming the Crisis of Confidence. Teachers College Press.

Marks, H.M. \& Louis, K.S. 1997. Does Teacher Empowerment Affect the Classroom? The Implications of TeacherEmpowerment for Instructional Practice and Student Academic Performance. Educational Evaluation and Policy Analysis, 19(3): 245-275. 
